\title{
LUKISAN CADAS: SIMBOLIS ORANG MALUKU
}

\section{Rock Painting: The Symbolic of People in The Moluccas}

\author{
Lucas Wattimena \\ Balai Arkeologi Ambon \\ J1. Namalatu - Latuhalat, Kecamatan Nusaniwe - Kota Ambon 97118 \\ Email : lucas.wattimena@yahoo.com
}

Naskah diterima: 08-01-2014; direvisi: 25-04-2014; disetujui: 09-05-2014

\begin{abstract}
Rock paintings in Moluccas has a core meaning and symbols in the life cycle of Moluccans in the past, present and future-future. Archaeological remains of rock paintings is a cultural interpretation of the past, where the construction of the values contained therein are an integral part of the social system of human culture the people of Moluccas. The values contained is the value of kinship, religion, grouping, knowledge, survival (survival strategy). Rock paintings in Ohoidertawun, Wamkana and Gulf Saleman have hinted that there are phases of any future development of human society. Research on how the rock paintings as archaeological remains, as the impact of the cultural value system and the structure of the rock painting itself. Performed in order to determine the value of the cultural and social system structure Moluccans rock paintings. The study of literature become the main reference of the study, with emphasis on past and present the data. From the research results prove that the archaeological remains of rock paintings have been contributing to the sociocultural meaning people of Moluccas, including the meaning of identity, culture and plurality or diversity.
\end{abstract}

Keywords: Painting the Rocks, Symbol Structure, Socio-Cultural System, Moluccans

\begin{abstract}
Abstrak
Lukisan cadas di Maluku memiliki inti makna dan simbol dalam siklus hidup Orang Maluku pada masa lampau, sekarang dan masa-masa yang akan datang. Tinggalan arkeologi lukisan cadas merupakan interprestasi kebudayaan masa lampau, dimana konstruksi nilai yang terkandung didalamnya adalah bagian integral dari sistim sosial budaya manusia masyarakat Maluku. Nilai-nilai yang terkandung adalah nilai kekerabatan, religi, pengelompokkan, pengetahuan, bertahan hidup (survival strategy). Lukisan cadas yang ada di Ohoidertawun, Wamkana dan Teluk Saleman telah memberikan petunjuk bahwa ada fase-fase perkembangan masyarakat manusia setiap masa. Penelitian tentang bagaimana lukisan cadas sebagai tinggalan arkeologis, sebagai dampak sistem nilai budaya dan struktur lukisan cadas itu sendiri. Dilakukan dengan tujuan untuk mengetahui sistem sosial nilai budaya dan struktur lukisan cadas Orang Maluku. Studi literatur menjadi acuan utama penelitian tersebut, dengan mengutamakan data terdahulu dan kini. Dari hasil penelitian membuktikan bahwa tinggalan arkeologis lukisan cadas telah memberikan kontribusi makna bagi sosial budaya Orang Maluku, diantaranya makna identitas, peradaban dan pluralitas atau kemajemukan.
\end{abstract}

Kata Kunci : Lukisan Cadas, Struktur Simbol, Sistem Sosial Budaya, Orang Maluku.

\section{PENDAHULUAN}

Lukisan cadas di Kepulauan Maluku dapat kita temukan di Pulau Seram, Buru dan Kepulauan Kei. Selain itu secara umum di
Indonesia lukisan -lukisan batu karang dapat di temui di Indonesia bagian timur, selain Kepulauan Maluku yaitu di Sulawesi Selatan, Nusa Tenggara Timur, Pulau Muna, dan Irian 
Jaya (Arifin, 1992 : 1). Dari hasil penelitian tersebut di temukan beberapa motif lukisan cadas yaitu berupa cap tangan, binatang, ikan, perahu, topeng muka. Berikut dapat di lihat tabel lukisan cadas berdasarkan lokasi situ arkeologi di Kepulauan Maluku :

Tabel 1: Jenis Lukisan Cadas Berdasarkan Situs Arkeologi di Maluku

\begin{tabular}{|c|c|c|}
\hline No. & Lokasi & Motif lukisan \\
\hline \multirow[t]{3}{*}{1} & Pulau Seram & Cap tangan \\
\hline & & Ikan \\
\hline & & $\begin{array}{l}\text { Binatang melata (kadal, } \\
\text { cicak) }\end{array}$ \\
\hline \multirow[t]{7}{*}{2} & Pulau Buru & Manusia menari \\
\hline & & Cap tangan \\
\hline & & Geometris \\
\hline & & Ikan \\
\hline & & Arah mata angin \\
\hline & & Perahu \\
\hline & & Bulatan/lingkaran \\
\hline \multirow[t]{5}{*}{3} & $\begin{array}{l}\text { Kepulauan Kei } \\
\text { Kecil }\end{array}$ & Matahari \\
\hline & & Kadal,cicak \\
\hline & & Cap tangan \\
\hline & & Topeng manusia \\
\hline & & Geometris \\
\hline
\end{tabular}

(Sumber : Data primer hasil penelitian).

Tinggalan arkeologis lukisan cadas adalah dinamika lapisan budaya manusia prasejarah yang dari waktu ke waktu merepresentasikan kebudayaan mereka dengan salah satu cara adalah melukis di dinding-dinding gua. Goresan di dinding-dinding batu adalah interprestas gagasan, ide manusia masyarakat dalam mengimplementasikan sikap sosial budaya terhadap siklus lingkungan, dimana manusia masyarakat itu berada.

Bachtiar seorang ahli kebudayaan merumuskan beberapa perangkat simbo dalam suatu kebudayaan, diantaranya simbolsimbol pengungkapan perasaan atau simbolsimbol ekspresif (dalam Munandar 2010: 71) Oleh sebab itu maka lukisan cadas dengan bentuk dan jenis motif apapun adalah bentuk simbol perasaan dari kebudayaan waktu manuanya, alam, lingkungan bahkan zaman itu. Hal ini bukan saja berhenti pada waktu itu tetapi sebagai social culture masyarakat manusia pada waktu itu, dan sifatnya kontiunitas. Arifin (1992), mengatakan bahwa lukisan batu karang, baik di alam terbuka atau ceruk maupun pada bongkahan batu di alam terbuka, merupakan salah satu unsur kebudayaa manusia prasejarah yang hidup berburu dan mengumpulkan makanan dan merupakan ekspresi kesenian pertama yang diperlihatkan oleh masyarakat sederhana ini (Arifin, 1992: 1). Adanya lukisan-lukisan ini menunjukan bahwa masyarakat pendukungnya bukanlah semata-mata masyarakat primitif yang tidak berbudaya, melainkan mereka sudah memiliki nilai-nilai keindahan dan keteraturan dalam mengekspresikan rasa keseniannya.

$$
\text { Pembicaraan dalam penulisan ini }
$$

nilai buday cadas. Tulisan ini mencoba memberikan gambaran informasi bagaimana bentukbentuk simbol Orang Maluku dan makna antropologi dan sosiologi dari lukisan cadas. Penulisan ini lebih memfokuskan kepada tinggalan arkeologis berupa lukisan cadas yang terdapat di Kepulauan Maluku dan tersebar di beberapa lokasi, yaitu Pulau Seram, Buru dan Kepulauan Kei Kecil.

\section{METODE}

Studi kepustakaan adalah pendekatan penelitian yang digunakan oleh penulis dalam menelaah permasalahan penelitian. Selain daripada itu penggunaan data terdahulu dan terkini juga dipergunakan dalam penulisan dimaksud.

Erwin Goodenough mendefinisikan simbol adalah barang atau pola, apapun sebabnya, bekerja pada manusia, dan berpengaruh pada manusia, melampui pengakuan semata-mata tentang apa yang disajikan secara harafiah dalam bentuk yang diberikan itu (dalam Dillistone, 2002: 19). Tinggalan arkeologis lukisan cadas dilihat

PROVINSI MALUKU

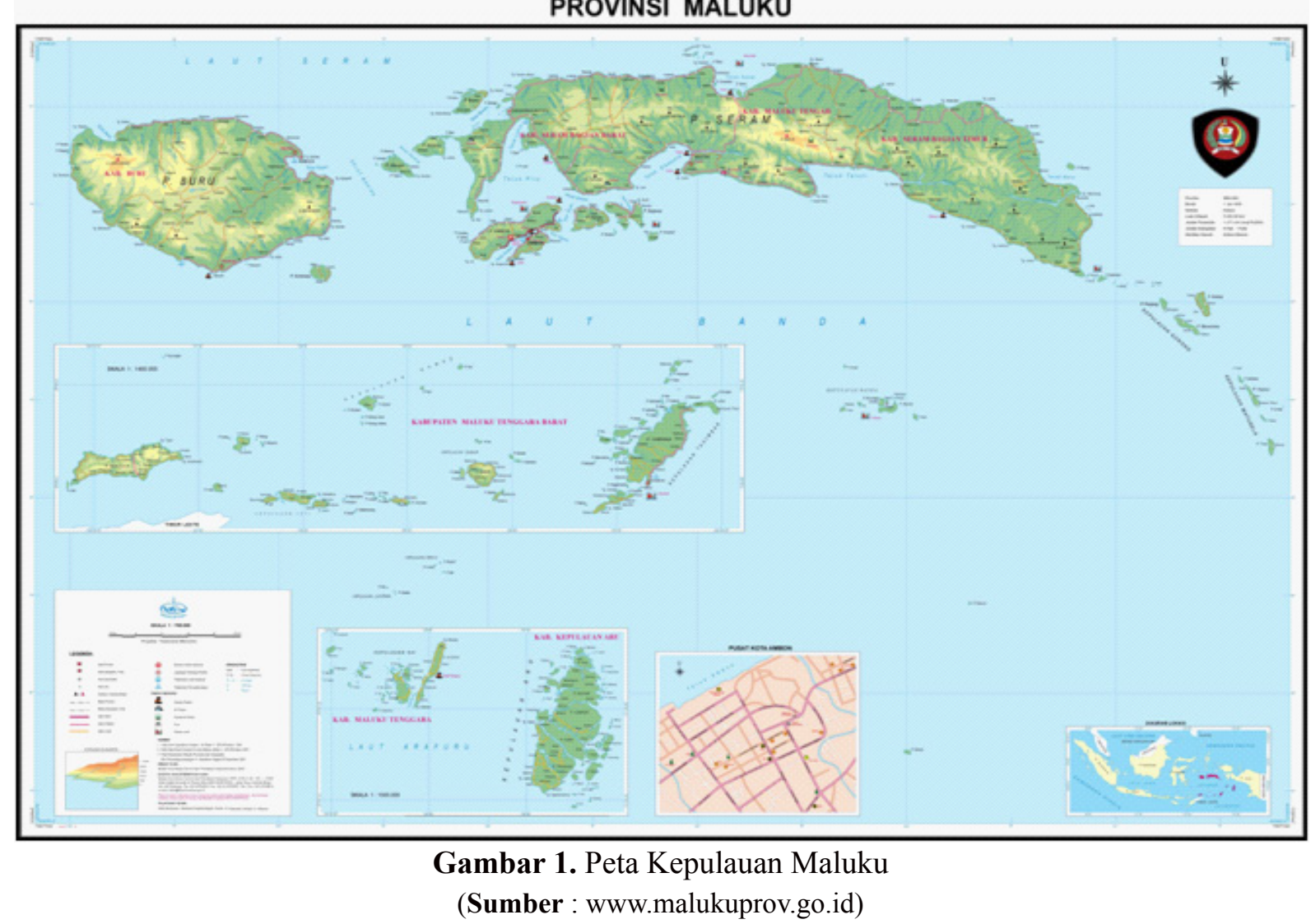

secara perspektif etnoarkeologi sebagai suatu identitas makna yang disampiakan lewat interaksi antara gambar-gambar, visualisasi, serta corak integrasi kelompok-kelompok manusia. Asikin menyebutkan bahwa teori migrasi selama ini menunjukan bahwa nenek moyang Orang Indonesia berasal dari Ras austromelanosoid. Ras in timur ke barat (dalam Handoko 2011: 118). Pendapat ini salah satunya mengungkapkan bahwa budaya lukisan cadas berasal dari Benua Australia yang merupakan cikal bakal Ras Austromelanosoid.

Parera menuliskan bahwa hampir seluruh daerah Indonesia bagian barat bahasanya secara generik termasuk sub rumpun bahasa Austronesia Baratdaya (termasuk kelompok Sulawesi Selatan, Muna-Butung, Bima-Sumba, dan lain-lain). Sedangkan wilayah Indonesia bagian timur termasuk sub rumpun bahasa Austronesia Timur, meliputi kelompok Ambon-Timor, Sula-Bacan, dan Halmahera Selatan-Irian Barat (Papua) (dalam Handoko 2011 : 118).
Tanudirjo (2011), memberikan gambaran tentang proses migrasi dan pesebaran para penutur Austronesia di Kawasan Indo-Pasifik. Mengikuti pola umum yang terjadi, migrasi jarak jauh biasanya dilakukan dengan cara Loncat Katak (leapfroggingprocess). Proses ini diawali dengan perjalanan penjajagan atau scouting untuk mencari daerah-daerah yang potensial untuk dihuni. Setelah mendapatkan informasi yang cukup, maka dilakukan migrasi dengan membawa serta sejumlah keluarga dengan membawa keluarag melewati daerah-daerah yang kurang berpotensi dan langsung menuju daerah yang diminati (Tanudirdjo, 2011 : 33). Secara regional lukisan cadas di Papua merupakan rangkaian dari seni lukisan cadas yang ada di wilayah Indonesia yang lain yaitu Sumatra (OKU), Kalimantan Timur, Sulawesi Selatan (Maros dan Pangkep), Sulawesi Tenggara (Pulau Muna), Maluku (Kei dan Seram). Persebaran kebudayaan tersebut mempunyai kaitan erat dengan persebaran bahasa Austronesia yang menghadirkan para 
pendukung kegiatan agrikultur di wilayah Asia Tenggara (Prasetyo, 2011: 88)

\section{HASIL DAN PEMBAHASAN}

\section{Sistem Nilai Budaya}

Lukisan cadas di Desa Wamkana Buru Selatan, Teluk Saleman Seram Utara dan Desa Ohoidertawun Kepulauan Kei adalah sebuah gagasan ide masyarakat manusia pada masa itu. Sistem nilai budaya melekat pada renteta kebudayaan lukisan cadas, implementas atas hasil karya manusia. Nilai, norma yang terkandung dalam lukisan-lukisan tersebut adalah pengekspresian perasaan, yang timbul atas dasar keingintahuan, kekuasaan, perjalanan, religi, kepercayaan dan sebagainya, sesuai bentuk dan sifat lukisan Van Wooden dalam kajiannya mengena struktur masyarakat bagian timur Indonesia menyatakan : cosmos in human society are organized in the same way, there emerges and essential interconnection and similarit of the human in the cosmic (Ajawaila, 1998 :5). Mengapa demikian, sebab lukisan cada adalah interprestasi alam yang mempunyai hubungan dengan manusia.

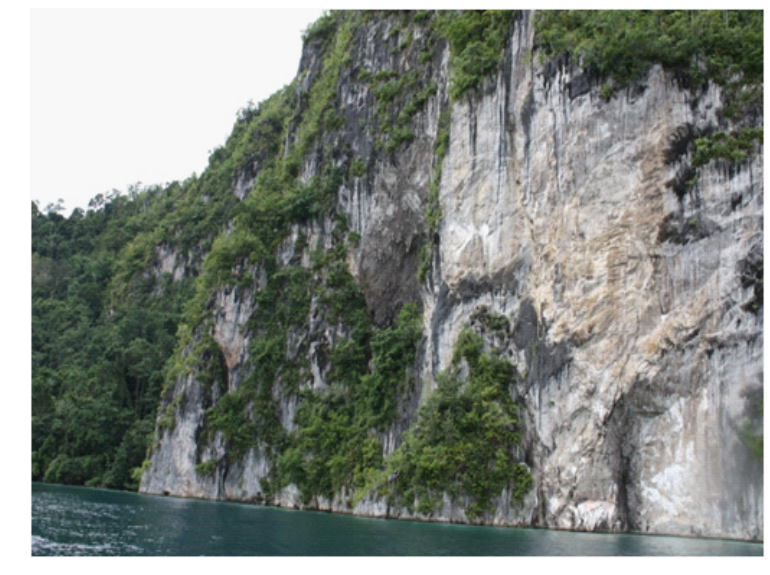

Daerah tebing temuan lukisan cadas di Teluk Saleman Pulau Seram

(Sumber : Dokumen Balai Arkeologi Ambon, 2009)

Manusia menghasilkan lukisan, dan itu adalah nilai budaya (gagasan, ide). Masyaraka manusia Maluku pada umumnya hidup dalam struktur kosmos, perpaduan antara baik buruk atas bawah, darat laut, laki-laki perempuan.
Huliselan keberadaan dan kenyataan hidup masyarakat Maluku saat ini tidak terlepas dari pengalaman sejarah orang-orang maluku secara berdiri sendiri maupun sebagai bagian dari bangsa Indonesia. Walaupun pada saa ini masyarakat yang mendiami kawasan kepulauan yang dinamakan Propinsi Maluku terdiri atas berbagai etnis tetapi penduduk aslinya menurut sumber termasuk orangorang Austronesia (dari pendekatan bahasa) (Huliselan, 2005 : 228). Dengan demikian selain bahasa lukisan gores pada dinding batu juga merupakan bagian sistem sosial budaya orang Austronesia.

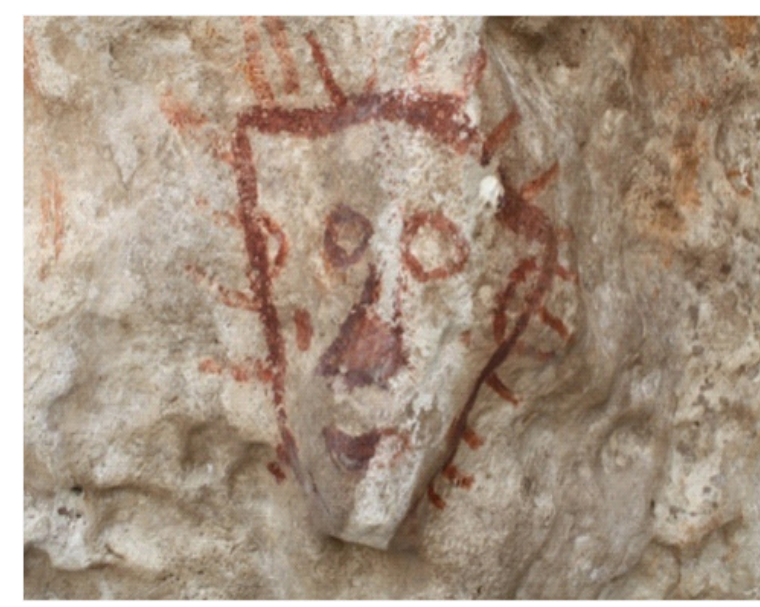

Gambar 3. Lukisan cadas motif wajah manusia (Sumber : Dokumen Balai Arkeologi Ambon, 2009)

Lukisan cadas motif cap tangan, manusia, perahu, binatang adalah pemaknaan simbol, dimana secara eksplisit sifa kebudayaan bercorak struktural-fungsional. Kenapa mereka harus menggambarkan motif-motif tersebut? Karena secara cultural holistic adalah pemahaman dasar akan makna sistemnilai budaya masyarakat. Cassier mengatakan bahwa simbol dihasilkan oleh manusia karena memang manusia itu adalah "hewan yang berpikir" (animal rational). Kebudayaan yang dihasilkannya pun sebagian merupakan refleksi simbolsimbol dalam alam kehidupannya, oleh karena itu manusia kemudian dinamakan juga animal symbolicum, dengan simbolsimbol tersebut manusia melangkah menuju peradaban (Munandar, 2010 : 71).
Huliselan (2005), menyebutkan bahwa identitas diri sangat diperlukan dalan relasi sosial agar yang satu dapat membedakan diri terhadap yang lain, dan yang satu dengan mudah mengenal yang lain, kerena perbedaan adalah mutlak penting. Perbedaan masing-masing dapat dilihat dalam ide-ide atau konsep-konsep yang abstrak, kelakuan berpola, organisasi dan pranata sosial sampai pada hasil-hasil karya (Huliselan, 2005 : 229). Lukisan cadas adalah konsep, gagasan dan ide suatu interprestasi identitas lewat karya-karya masyarakat manusia pada waktu itu, bahkan sebagai penanda identitas demi keseimbangan sistem sosal budaya masyarakat man masa-masa mendatang.

\section{Struktur Simbol Lukisan Cadas Sebagai} Kebudayaan

Redfield beranggapan bahwa kebudayaan folk dapat diteliti dengan sebaikbaiknya dalam suatu bentuk masyarakat yang disebut little community atau komuniti kecil. Komuniti sebagai suatu satuan sosial yang utuh yang terikat pada suatu tempat dengan ciri-ciri alamiah khas, sehingga merupakan bagian dari suatu sistem ekologi yang bulat (dalam Koentjaraningrat, 1990 : 139).

Tinggalan arkeologis berupa lukisan cadas, secara ekplisit merupakan tatanan ekologi peradaban manusia pada masa itu. Dimana komunitas-komunitas kecil yang berkelompok (seperti kelompok matarumah/ fam/marga) mereka berkelompok untuk melanjutkan rantai kehidupan. Pikiranpikiran, sikap, tindakan mereka pada waktu itu adalah substansi pokok pemaknaan simbol maksud dan tujuan ketika mereka melakukan pelukisan-pelukisan pada dindingdinding batu. Whitehead dalam bukunya symbolism Ia menulis pikiran manusia berfungsi secara simbolis apabila beberapa komponen pengalamannya menggugah komponen pengalamannya menggugah
kesadaran, kepercayaan, perasaan, dan kesadaran, kepercayaan, perasaan, dan lain pengalamannya. Perangkat komponen yang terdahulu adalah "simbol" dan perangkat komponen yang kemudian membentuk "makna simbol" (Dillinstone, $2002: 18$ ). Berbagai motif seperti yang telah dijelaskan sebelumnya, adalah bagian dari struktur simbol dan pemaknaan simbol. Misalnya motif cap tangan; lukisan cadas cap tangan pada dinding batu di Desa Wamkana Kabupaten Buru Selatan mencirikan interprestasi dari simbol, dimana pikiran, perasaan yang ada pada lukisan cap tangan itu, kemudian pemaknaan akan bentuk, warna jenis adalah pemaknaan simbol. Sejauh mana dan berdampak seperti apa lukisan cadas motif cap tangan terhadap kehidupan sosia budaya waktu itu dan akan menjadi tolak ukur dinamika kebudayaan pada masa-masa mendatang. Dengan kata lain struktur simbol lukisan cadas adalah kebudayaan. Struktur simbol lukisan cadas pada dasarnya adalah kebudayaan. Sistem sosial budaya yang terkandung dalam kebudayaan merupakan suatu interaksi, integrasi manusia dengan alam lingkungan sekitar, manusia dengan manusia.

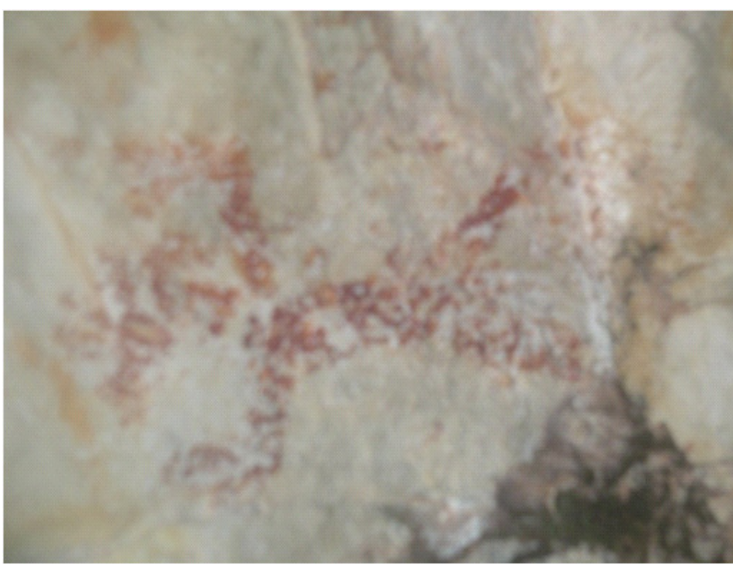

Gambar 4. Lukisan motif manusia (Sumber : Dokumen Balai Arkeologi Ambon, 2009)

Lukisan cadas di Desa Wamkana Buru Selatan, Teluk Saleman Seram Utara dan Desa Ohoidertawun Kepulauan Kei adalah sebuah gagasan ide masyarakat manusia pada masa itu. Struktur simbol lukisan cadas melekat pad rentetan kebudayaan yang diimplementas atas hasil karya manusia. Terkandung nilai, norma yang terkandung dalam lukisan-lukisan tersebut adalah pengekspresian perasaan, yang timbul atas dasar keingintahuan, 
kekuasaan, perjalanan, religi, kepercayaan dan sebagainya, sesuai bentuk dan sifat lukisan. Arifin (1996), menyebutkan lukisan batu karang, baik dalam gua atau ceruk maupun pada bongkahan batu di alam terbuka, merupakan salah satu unsur kebudayaan manusia prasejarah yang hidup dari berburu dan mengumpulkan makanan dan merupakan ekspresi kesenian pertama yang diperlihatkan olej masyarakat sederhana ini (Arifin, 1996: 1). Adanya lukisan-lukisan ini menunjukan bahawa masyarakat pendukungnya bukanlah semata-mata masyaraakat primitif yang tidak berbudaya, melainkan mereka sudah memiliki nilai-nilai keindahan dan keteraturan dalam mengekspresikan rasa keseniannya.

Handoko (2009), memberikan pembagian atas motif-motif lukisan cadas di Ohoiderwatun dalam beberapa kategori, yaitu :

1. Kelompok Lukisan Manusia. Dar kelompok lukisan yang mewakili lukisan manusia terdapat beberapa penggambaran gaya, antara lain :

a. Lukisan manusia yang divisualisasikan dengan motif lukisan manusia sederhana, manusia menari, manusia jongkok dengan ciri khas hiasan kepala dan manusia dalam posisi sedang bertarung (perang).

b. Lukisan cap tangan, baik negatif maupun positif dengan warna lukisan dominan merah dan sebagian lain berwarna kuning.

c. Lukisan topeng manusia dengan bentuk kepala segitiga dan bula dengan ciri berambut dan tidak berambut pada kepalanya.

2. Kelompok Lukisan Fauna:

. Lukisan binatang Air

b. Lukisan kadal

c. Lukisan perahu, menampilkan desain lukisan yang dinamis, dimana terdapat lukisan perahu sederhana dan lukisan perahu yang mengesankan membawa muatan d. Lukisan Non Figuratis : garis, Lingkaran, geomtris dan visualisasi matahari (Handoko, 2009: 19-20).

Keberagaman pemaknaan simbol lukisan cadas adalah keberagaman budaya dan tingkatan pengetahuan manusia pada waktu itu, dengan representatif perasaan pada lukisan di dinding batu.

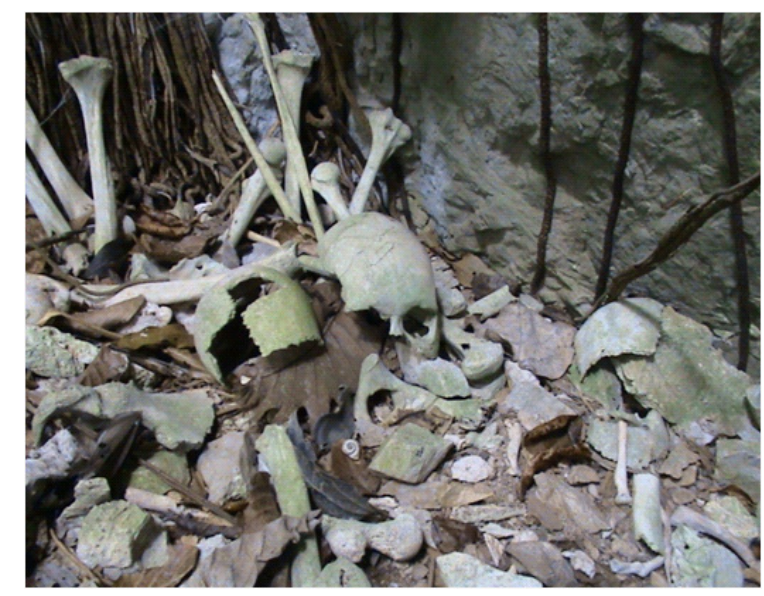

Gambar 5. Temuan tulang di sekitar lokasi lukisan cadas di Sawai Pulau Seram

(Sumber : Dokumen Balai Arkeologi Ambon, 2009)

Budaya tutur adalah salah satu kearifan masyarakat Maluku atas setiap tindakan, sikap dan prilaku sosial buday yang berlangsung dalam masyarakat. Hampir semua pemaknaan lukisan cadas masyaraka setempat sudah tidak tahu lagi, hanya lewat folklore; hubungan-hubungan integrasi akan fenomena alam, lingkungan dengan manusia masyarakatnya.

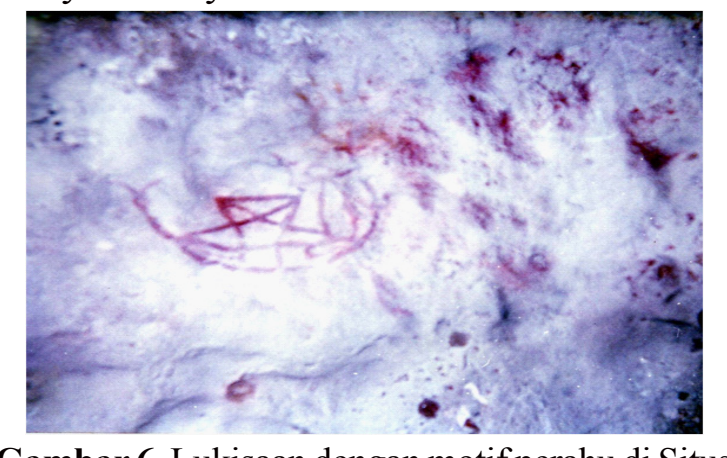

Dudumahan Maluku Tenggara

(Sumber : Dokumen Balai Arkeologi Ambon, 2009)
Arifin (1996), menafsirkan lukisan batu karang di Indonesia hampir selalu disertai dengan penafsiran mengenai fungsi dan maknanya. Namun, karena bentuk kesenian ini sering kali berasal dari mana yang sangat kuna dan tidak lagi diketahui fungsi serta maknanya, maka pemahamaannyaa hanya dapat diperoleh berdasarkan dugaan dan analogi (2011), mengatakan bahwa tema perahu salah satunya di interprestasikan lewat lukisan cadas (Ririmasse, 2011: 14). Menurut teoritis interaksi simbolik, kehidupan sosial pada dasarnya adalah interaksi manusia dengan menggunakan simbol-simbol (Mulyana, 2010 : 70-71). Tinggalan arkeologis lukisan cadas adalah prilaku-prilaku manusia sebagai proses interaksi, baik dengan sesama manusia, alam, dan sebagainya. Hal demikian adalah subjektifitas manusia masyarakat Maluku khususnya dan Indonesia umumnya.

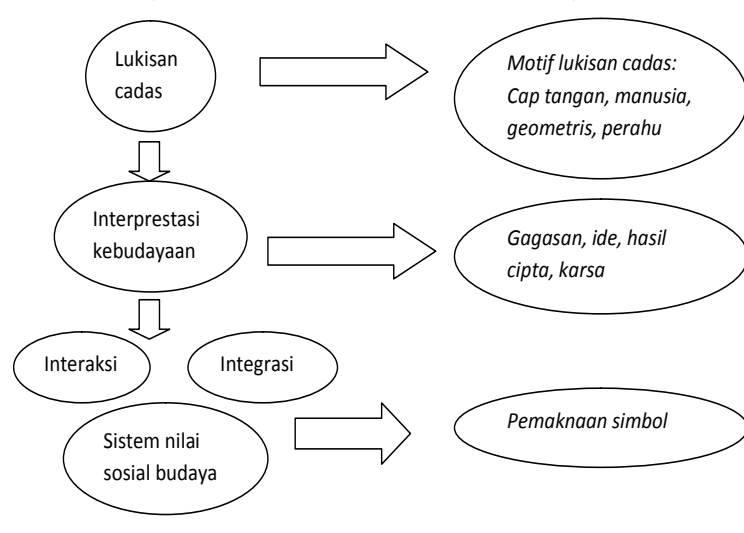

Gambar 7. Struktur lukisan cadas di Kepulauan Maluku

\section{PENUTUP}

Kajian sosiologis antropologis terhadap lukisan cadas merepresentasikan simbol makna, antara lain : Identitas; sebagai suku bangsa tertentu dalam suatu wilayah pemaknaan identitas sangat penting, disebabkan karna identitas adalah simbol yang dapat memberikan pemaknaan secara verbal atas struktur sosial suatu suku bangsa/ masyarakat tertentu. Peradaban budaya; proses perkembangan kebudayaan sifatnya dinamis, tidak statis sehingga kebudayaan tersebut selalu mengalami peradaban- peradaban baru, sesuai kausalitas konkrit kebudayaan itu sendiri. Kemajemukan atau pluralitas manusia; pada pemaknaan ini, adalah proses setelah identitas, dan peradaban budaya. Puncak akan keberagaman sosia budaya manusia masyarakat yang hidup berdampingan, berinteraksi serta berintegras.

\section{$* * * * *$}

\section{DAFTAR PUSTAKA}

Ajawaila. 1998. Kosmologi Orang Wemale di Seram Barat. Maluku. Proyek Pengkajian Maluku. Departemen Pendidikan dan Kebudayaan.

Arifin, Karina. 1996. Lukisan Batu Karang De Indonesia Suatu Evaluasi Hasi Kebudayaan. Kampus Depok. Lembaga Penelitian Universitas Indonesia.

Dillistone, F. W. 2002. Terjemahan Widyamartaya Daya Ke
Kanisius.

Handoko, Wuri. 2009. Laporan Penelitian Arkeologi Prasejarah di Kepulauan Ke Arkeologi Ambon.

Handoko, Wuri. 2011. Budaya Austronesia di Kepulauan Maluku. Autronesia dan Asal Usul dan Jati Diri Dari Temuan Arkeologis. Hal. 107-122. Yogyakarta: Penerbit Ombak.

Huliselan, Mus. 2005. Berdampingan Dalam Menyambut Masa Depan. Ambon: Lembaga Kebudayaan Daerah Maluku. Hal 222-244.

Koentjaraningrat. 1990. Sejarah Teori Antropologi II. Jakarta. UI Press.

Mulyana, Deddy. 2010. Metodologi Penelitian ualitatif. Bandung. PT. Remaj Rosdakarya. 
Munandar, Agus Aris. 2010. Simbolisme Kepurbakalaan Megalitik Di Wilayah Pagar Alam, Sumatra Selatan. Pentas Ilmu Di Ranah Budaya. Pusataka Larasan. Denpasar Bali. Hal 68-87.

Prasetyo, Bagyo. 2011. Budaya Pantai dan Pedalaman Masa Prasejarah di Papua. Autronesia dan Melanesia di Nusantara; Mengungkap Asal Usul dan Jati Diri Dari Temuan Arkeologis. Hal. 75-94. Yogyakarta: Penerbit Ombak.

Ririmase, Marlon. 2011. Perahu Sebagai Simbol Di Maluku Tenggara; Suatu Pengantar. Kapata Arkeologi (Jurnal Arkeologi Wilayah Maluku dan Maluku Utara) Hal 1-17. Vol. 7 No. 12 Juli. Ambon: Balai Arkeologi Ambon.

Tanudirjo, Daud. 2011. Interaksi AustronesiaMelanesia; Kajian Interprestasi Teoritis. Autronesia dan Melanesia di Nusantara; Mengungkap Asal Usul dan Jati Diri Dari Temuan Arkeologis. Autronesia dan Melanesia di Nusantara; Mengungkap Asal Usul dan Jati Diri Dari Temuan Arkeologis. Hal. 23-42. Yogyakarta: Penerbit Ombak. 